\title{
Research Article \\ Effects of Precursor-Substrate Distances on the Growth of GaN Nanowires
}

\author{
Hongbin Cheng, ${ }_{1}^{1}$ Jia Li, ${ }^{2}$ Dongxu Wu, ${ }^{2}$ Yanxi Li, ${ }^{3}$ Zhiguang Wang, \\ Xianying Wang, ${ }^{1}$ and Xuejun Zheng ${ }^{1}$ \\ ${ }^{1}$ School of Materials Science and Engineering, University of Shanghai for Science \& Technology, Shanghai 200093, China \\ ${ }^{2}$ School of Mechanical Engineering, University of Shanghai for Science \& Technology, Shanghai 200093, China \\ ${ }^{3}$ Department of Materials Science and Engineering, Virginia Tech, Blacksburg, VA 24061, USA \\ ${ }^{4}$ Harvard Medical School, Boston, MA 02114, USA
}

Correspondence should be addressed to Xianying Wang; xianyingwang@usst.edu.cn and Xuejun Zheng; zhengxuejun@usst.edu.cn

Received 18 March 2015; Revised 19 July 2015; Accepted 22 July 2015

Academic Editor: Mohamed Bououdina

Copyright (C) 2015 Hongbin Cheng et al. This is an open access article distributed under the Creative Commons Attribution License, which permits unrestricted use, distribution, and reproduction in any medium, provided the original work is properly cited.

\begin{abstract}
$\mathrm{GaN}$ nanowires were synthesized through the Ni-catalyzed chemical vapor deposition (CVD) method using $\mathrm{Ga}_{2} \mathrm{O}_{3} / \mathrm{GaN}$ mixtures as gallium sources, and precursor-substrate distances were investigated as the important factor for the growth of GaN nanowires. The microstructure, composition, and photoluminescence property were characterized by X-ray diffraction, field emission scanning electron microscopy, high-resolution transmission electron microscopy, and photoluminescence spectra. The results showed that single crystalline GaN nanowires with the diameter of about $90 \mathrm{~nm}$ and the length up to tens of micrometers had been grown thickly across $\mathrm{Si}(100)$ substrates with uniform density. Moreover, the variations of the GaN nanowire morphology, density, and size were largely attributed to substrate positions which would influence Ga precursor density in the carrier gas, the saturation degree of gaseous reactants, and the catalyst activity, respectively, in the fabrication of GaN nanowires by the vapour liquid solid mechanism.
\end{abstract}

\section{Introduction}

One-dimensional semiconductor nanostructures are emerging as versatile nanoscale building blocks for future nanotechnologies in terms of their innovative physical properties and potential applications in electronic and photonic nanodevices [1]. GaN, a robust wide band gap semiconductor, has attracted much attention for its novel optical, electrical, and mechanical properties [2]. GaN nanowires have also shown great potential applications in nanodevices, such as blue light emitting diode [3], short-wavelength ultraviolet nanolaser [4], field effect transistor [5], Schottky diode [6], and field emitter [7]. To date, a series of methods, such as laser ablation [8], carbon-nanotube-confined reactions [9], hydride vapor phase epitaxy $[10,11]$, metal organic chemical vapor deposition (MOCVD) [12-14], and chemical vapor deposition (CVD) $[15,16]$, have been utilized to synthesize GaN nanowires. Due to low cost and simplicity, the chemical vapor deposition has been way ahead of other methods reported in the literature, and different gallium sources such as $\mathrm{Ga}[17,18], \mathrm{Ga}_{2} \mathrm{O}_{3}[19,20], \mathrm{GaN}[21,22], \mathrm{Ga}_{2} \mathrm{O}_{3} / \mathrm{Ga}[12]$, and $\mathrm{Ga} / \mathrm{GaCl}_{3}$ [23] have been employed. Moreover, it was found that mixed source materials are much better for the growth of $\mathrm{GaN}$ nanowires than the single gallium source. $\mathrm{Ga}$ bulk and $\mathrm{Ga}_{2} \mathrm{O}_{3}$ powder cannot be uniformly mixed [12], and $\mathrm{GaCl}_{3}$ is deliquescent in air and needs to be operated in particular device [23]. Fortunately, the study showed that $\mathrm{Ga}_{2} \mathrm{O}_{3}$ and $\mathrm{GaN}$ powder could be mixed uniformly and they were not deliquescent in air. Meanwhile, the mixed gallium source can also provide high and stable gallium density in the carrier gas during the reaction. Thus, it is attractive to use the $\mathrm{Ga}_{2} \mathrm{O}_{3} / \mathrm{GaN}$ mixtures as the gallium source for the fabrication of high quality $\mathrm{GaN}$ nanowires through the CVD process. In addition, although there are reports about effects of precursor-substrate distances on the synthesis of nanowires [24], these researches did not explore 


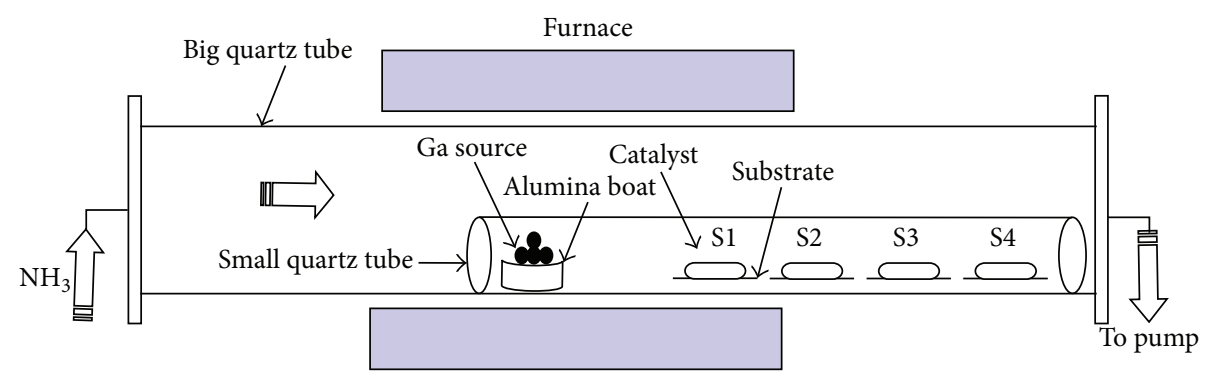

FIGURE 1: Schematic apparatus for the synthesis of GaN nanowires.

in detail the best position for the CVD growth of GaN nanowires. Therefore, investigation of effects of precursorsubstrate distances on the growth of GaN nanowires, whereby a simple and repeatable process for the large fabrication of high quality GaN nanowires still has considerable appeal.

In this paper, $\mathrm{GaN}$ nanowires were synthesized on $\mathrm{Ni}$ coated $\mathrm{Si}$ substrates via the CVD method. $\mathrm{Ga}_{2} \mathrm{O}_{3} / \mathrm{GaN}$ mixtures as the gallium sources and the substrate positions were investigated as the important factors for the growth of $\mathrm{GaN}$ nanowires. The microstructure, composition, and photoluminescence property were characterized by X-ray diffraction, field emission scanning electron microscopy, high-resolution transmission electron microscopy, and photoluminescence spectra. The results showed that substrate positions had important influence on the controllable fabrication of $\mathrm{GaN}$ nanowires by the vapour liquid solid mechanism.

\section{Experimental}

$\mathrm{GaN}$ nanowires were grown by the CVD process at $1100^{\circ} \mathrm{C}$. Figure 1 shows the schematic apparatus for the synthesis of $\mathrm{GaN}$ nanowires. In the experiment, a layer of $\mathrm{Ni}$ catalyst ( $3 \mathrm{~nm}$ thick) was thermally evaporated onto a Si (100) substrate. The substrates were cleaned by the ultrasonic cleaning machine with acetone, ethanol, and deionized water for $30 \mathrm{~min}$ in sequence. After baking, the substrates were employed for the synthesis of nanowires. The alumina boat containing $0.1172 \mathrm{~g}$ gallium source and the substrate were put into a small quartz tube sequentially. Then, the small quartz tube was placed in a tube furnace (Lindberg blue, Thermo Scientific, Waltham, MA, USA) where the alumina boat was located in the center. The tube furnace was evacuated and flushed with Ar for $10 \mathrm{~min}$ and ramped at $30^{\circ} \mathrm{C} / \mathrm{min}$ to the growth temperature $\left(1100^{\circ} \mathrm{C}\right)$ in the flowing Ar atmosphere $(20 \mathrm{sccm}$, standard cubic centimeters per minute). $30 \mathrm{sccm} \mathrm{NH} \mathrm{NH}_{3}$ was introduced instead of Ar after the temperature reached $1100^{\circ} \mathrm{C}$ and the furnace was kept at the growth temperature for $30 \mathrm{~min}$. Finally, the system cooled down to room temperature in the Ar environment.

Four samples were prepared according to the different precursor-substrate distances (sample S1: $10 \mathrm{~cm}$, sample S2: $11 \mathrm{~cm}$, sample $S 3: 12 \mathrm{~cm}$, and sample $S 4: 13 \mathrm{~cm}$ ) from the gallium source. The surface morphology, microstructure, and composition of the GaN nanowires were characterized by scanning electron microscopy (SEM, FEI Quanta FEG), transmission electron microscopy (TEM, FEI Tecnai G2), high-resolution transmission electron microscopy (HRTEM, FEI Tecnai G2), and X-ray diffraction (XRD, Bruker D8 Advance $\mathrm{Cu}-\mathrm{K} \alpha$ ). Room temperature photoluminescence (PL) spectra were carried out by using $325 \mathrm{~nm} \mathrm{He}-\mathrm{Cd}$ laser as the excitation source.

\section{Results and Discussion}

Figure 2 shows the representative SEM images of grown samples. Long and straight $\mathrm{GaN}$ nanowires were largely synthesized using $\mathrm{Ga}_{2} \mathrm{O}_{3} / \mathrm{GaN}$ mixtures as gallium sources on the $\mathrm{Si}$ substrates. It is also interesting to note that the physical aspects of the synthesized GaN nanowires were significantly different for substrate positions $(10 \mathrm{~cm}, 11 \mathrm{~cm}$, $12 \mathrm{~cm}$, and $13 \mathrm{~cm}$ ) as shown in Figures 2(a), 2(b), 2(c), and 2(d). For sample S1, there are no nanowires but only some stacking structures. For sample S2, long and straight GaN nanowires with the length up to tens of micrometers were grown thickly across the whole substrate with uniform density. For sample S3, most of the GaN nanowires were zigzag with distorted shape. As for sample S4, the diameter of nanowires was nonuniform with stack surface. Thus, GaN nanowires grown at the substrate position of $11 \mathrm{~cm}$ have smooth surface and straight morphology, much better than other positions. Based on the SEM results, the precursorsubstrate distances seem to have big influences on the surface morphology and microstructure of grown GaN nanowires.

$\mathrm{X}$-ray diffraction (XRD) spectra of the GaN nanowires for four samples are shown in Figure 3. The peak intensity of substrate $\mathrm{Si}$ is too strong and has been omitted in order to clearly display other peaks in the XRD diagram. All the peaks (100), (002), (101), (102), (110), and (103) can be indexed to the hexagonal wurtzite structure of $\mathrm{GaN}$ with lattice constants of $a=0.319 \mathrm{~nm}$ and $c=0.519 \mathrm{~nm}$, same as the standard card (JCPDS 76-0703). Moreover, $\mathrm{Ga}_{2} \mathrm{O}_{3}$ peaks are not present in the original diffraction peaks of XRD. With comparison of XRD spectra for the different substrate positions, the intensity of three major GaN peaks (100), (002), and (101) in sample S2 was stronger than that in samples S1, S3, and S4. The result indicates that the crystalline quality of nanowires grown by the substrate positions of $11 \mathrm{~cm}$ is significantly improved which is consistent with the above SEM analysis.

Further structural characterization of samples S2 and S3 was performed by TEM and high-resolution TEM (HRTEM) 


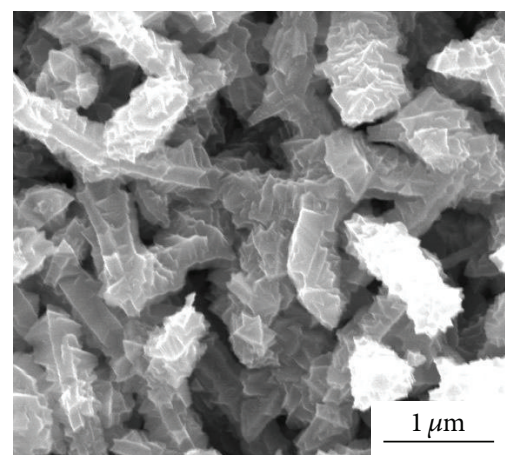

(a)

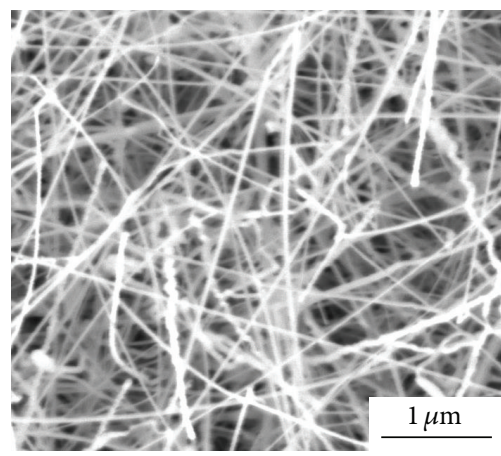

(c)

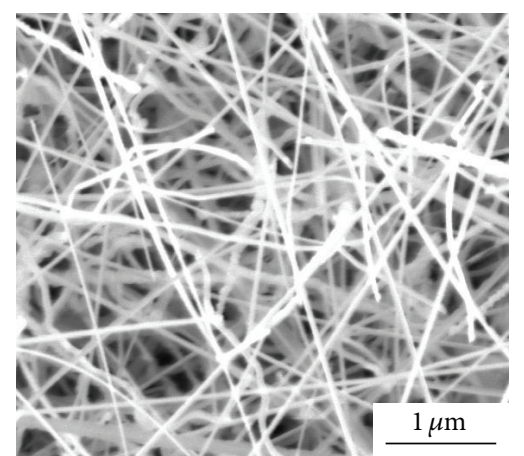

(b)

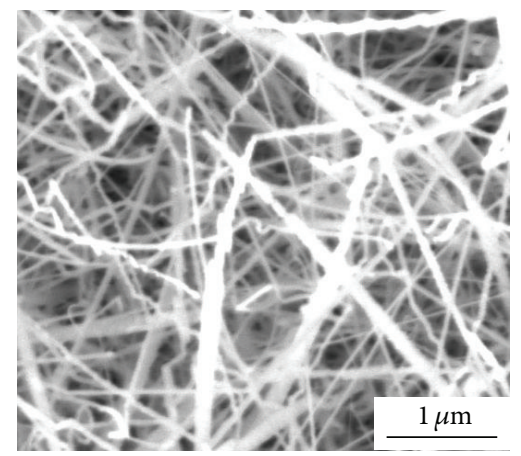

(d)

FIGURE 2: SEM images of samples (a) S1, (b) S2, (c) S3, and (d) S4.

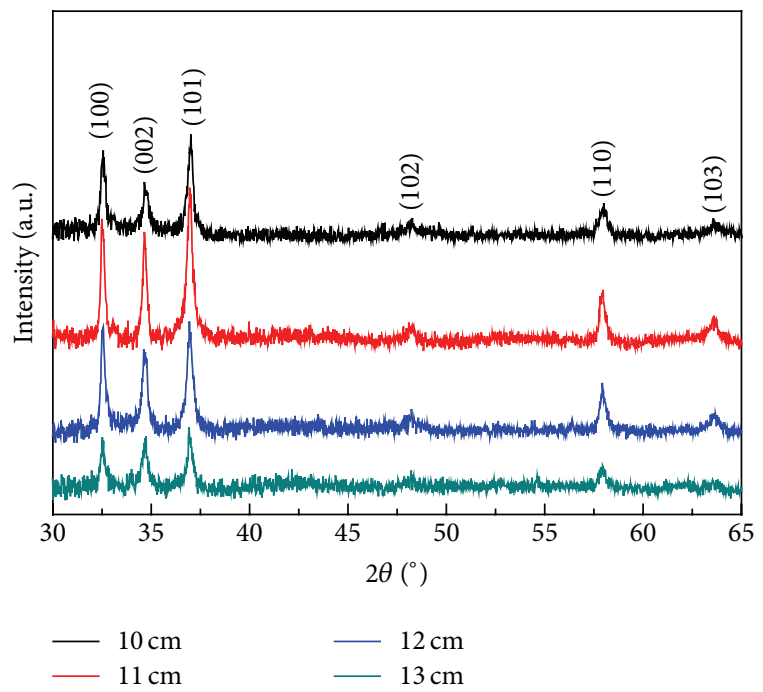

FIGURE 3: The XRD spectra of samples S1, S2, S3, and S4.

as depicted in Figure 4. S1 and S4 are not investigated due to their poor SEM results. Figure 4(a) shows the lower-amplified TEM image of sample S2, a single nanowire with a diameter of about $90 \mathrm{~nm}$, which is straight and smooth. Figure 4(b) shows the HRTEM lattice image of sample S2; the visible lattice fringes illustrate that the nanowire is single crystal in nature. The interplanar spacing accurately measured is
$0.24 \mathrm{~nm}$, which corresponds to the (101) plane of hexagonal GaN. Figures 4(c) and 4(d) are images of sample S3. The straight nanowire with a diameter of about $60 \mathrm{~nm}$ is shown in Figure 4(c). Based on the HRTEM image (Figure 4(d)), the interplanar spacing accurately measured is $0.276 \mathrm{~nm}$, which corresponds to the (100) plane of hexagonal GaN. Those conclusions are also consistent with the XRD results.

The growing procedures of GaN nanowires with different substrate positions are schematically illustrated in Figure 5. $\mathrm{NH}_{3}$ decomposes to $\mathrm{NH}_{2}, \mathrm{NH}, \mathrm{H}_{2}$, and $\mathrm{N}$ successively when ammoniating temperature is above $850^{\circ} \mathrm{C}$ [25]. The $\mathrm{Ga}_{2} \mathrm{O}_{3}$ particles are reduced to gaseous $\mathrm{Ga}_{2} \mathrm{O}$ by $\mathrm{H}_{2}$ and then $\mathrm{GaN}$ molecules are synthesized through the reaction of $\mathrm{Ga}_{2} \mathrm{O}$ and ammonia [26]. When the temperature rises to $1000^{\circ} \mathrm{C}, \mathrm{GaN}$ begins to decompose the raw Ga species and react with $\mathrm{NH}_{3}$ to generate $\mathrm{GaN}$ [24]. Meanwhile, it is noted that a single $\mathrm{Ga}_{2} \mathrm{O}_{3}$ source produces low gallium density in the carrier gas during the heating process, which will result in uneven or disorder growth of nanowires. When only $\mathrm{GaN}$ is used as the gallium source, GaN starts to break down to generate $\mathrm{Ga}$ and nitrogen in the nitrogen atmosphere at $1050^{\circ} \mathrm{C}$; however, the decomposed Ga species are evaporating fast which is a disadvantage for continual growth of nanowires. While the $\mathrm{Ga}_{2} \mathrm{O}_{3} / \mathrm{GaN}$ mixtures are exploited, $\mathrm{Ga}_{2} \mathrm{O}_{3}$ is first broken down to generate $\mathrm{Ga}_{2} \mathrm{O}$ when the temperature is higher than $850^{\circ} \mathrm{C}$, and $\mathrm{GaN}$ nanowires can be gotten by ammoniation. After the temperature further increases to $1000^{\circ} \mathrm{C}, \mathrm{GaN}$ will decompose $\mathrm{Ga}$ species into the carrier gas which will improve the Ga density to help synthesize GaN nanowires during 


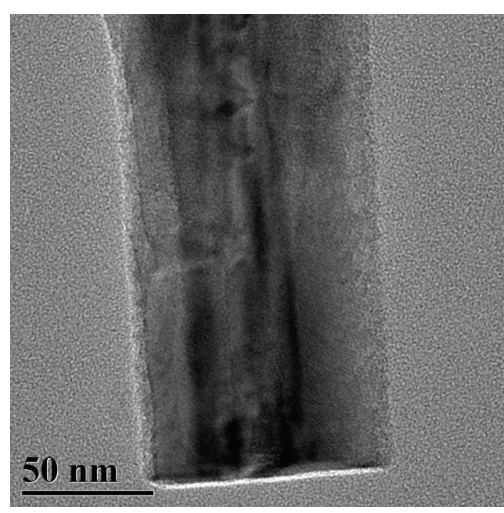

(a)

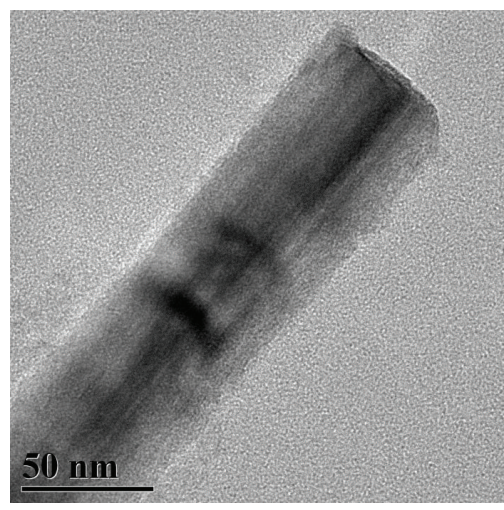

(c)

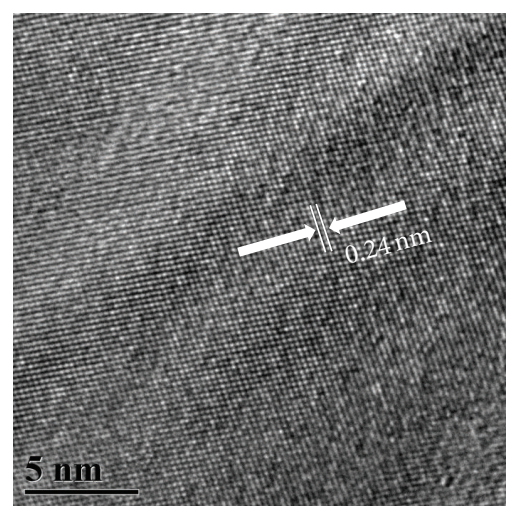

(b)

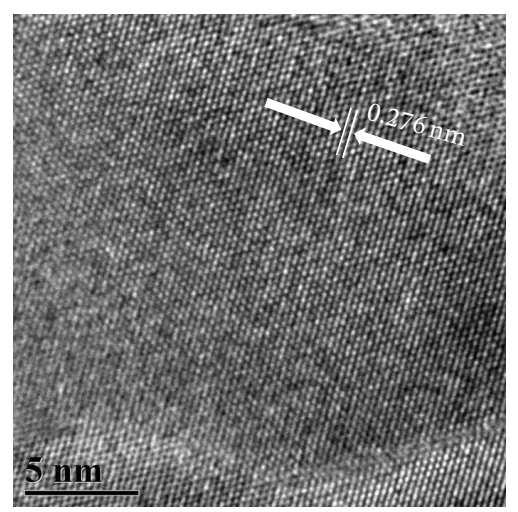

(d)

Figure 4: TEM (a) and HRTEM (b) images of sample S2. TEM (c) and HRTEM (d) images of sample S3.

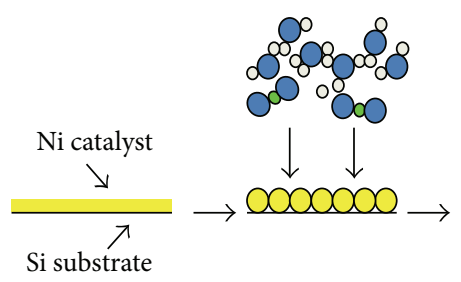

O Ni droplet

do Ni-Ga-N liquid alloy of $\mathrm{GaN}$
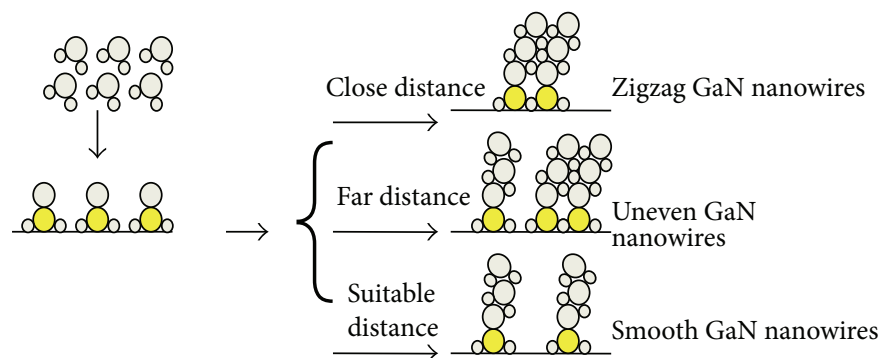

FIGURE 5: Schematic model illustrating the GaN nanowires growth with different distances.

the reaction. Based on the vapour liquid solid (VLS) mechanism, the $\mathrm{Ni}-\mathrm{Ga}-\mathrm{N}$ alloy droplets are formed on the substrate as nucleation sites for the growth of GaN microwires. When the concentration of the $\mathrm{Ga}-\mathrm{N}$ flux exceeds the saturation point within the $\mathrm{Ni}-\mathrm{Ga}-\mathrm{N}$ droplets, $\mathrm{GaN}$ nanowires are obtained [26, 27]. Here the saturation degree of gaseous reactants and the catalyst activity are highly dependent on the substrate position [24]. As the substrate is $10 \mathrm{~cm}$ away from the gallium source where the temperature is about $980^{\circ} \mathrm{C}$, a large number of stacking and disordered nanostructures are formed in a short period of time due to the fast precipitation nucleation speed. As the substrate is $11 \mathrm{~cm}$ away from the gallium source with the temperature of about $950^{\circ} \mathrm{C}$, the gas flow, reaction temperature, and gas concentration are most suitable for the nucleation and growth. However, as the distance increases to $12 \mathrm{~cm}$ with the temperature of $930^{\circ} \mathrm{C}$, the catalyst activity and the concentration of the reactant species decrease. Thus, the slow reaction rate results in the instable and uneven growth. As the location is farther away from the gallium source, the growing condition is worse for 


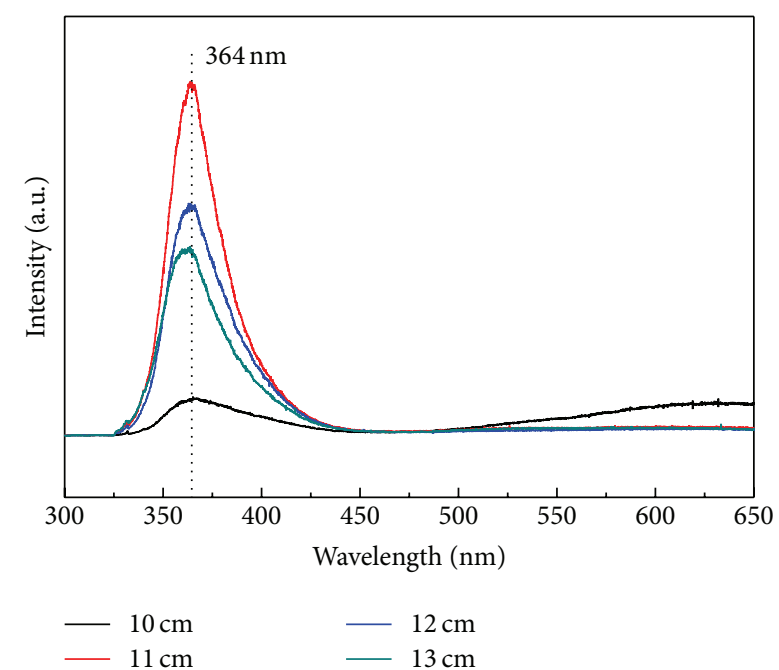

FIGURE 6: Room temperature PL spectra of samples S1, S2, S3, and S4.

the formation of GaN nanowires, and even a small amount of film is deposited on the substrate. As a result, the substrate position has great influence on the growth of $\mathrm{GaN}$ nanowires.

A $325 \mathrm{~nm} \mathrm{He}-\mathrm{Cd}$ UV laser was used as the excitation light source, and typical room temperature PL spectra for GaN Nanowires are illustrated in Figure 6. The band-edge emission peaks for all four samples are located at the wavelength of $364 \mathrm{~nm}$ which were caused by the interband transition [20]. When the distance between the substrate and the gallium source increased from $10 \mathrm{~cm}$ to $13 \mathrm{~cm}$, the emission peak almost kept the same position, but the intensity gradually changed and reached the highest value at a distance of $11 \mathrm{~cm}$. Therefore, the substrate positions have great influence on the optical properties of $\mathrm{GaN}$ nanowires. For $11 \mathrm{~cm}$ samples, the emission peak caused by the interband transition is strong and narrow, and no other luminescence peak was induced by impurities and defects, indicating that high crystalline GaN nanowires have been synthesized via the CVD method. Moreover, for $10 \mathrm{~cm}$ samples an emission peak at the wavelength of $620 \mathrm{~nm}$ was found which might be due to the $\mathrm{Ga}$ and $\mathrm{N}$ vacancies in $\mathrm{GaN}$ crystals [28].

\section{Conclusions}

GaN nanowires were successfully synthesized on Ni-coated $\mathrm{Si}$ (100) substrates using $\mathrm{Ga}_{2} \mathrm{O}_{3} / \mathrm{GaN}$ mixtures as gallium sources. With the substrate position $11 \mathrm{~cm}$ away from the gallium source, single crystalline GaN nanowires with the diameter of about $90 \mathrm{~nm}$ and the length up to tens of micrometers had been grown thickly across the substrate with uniform density. It is also found that substrate positions have large effects on Ga precursor density in the carrier gas, the saturation degree of gaseous reactants, and the catalyst activity, respectively, in the fabrication of $\mathrm{GaN}$ nanowires by the vapour liquid solid mechanism.

\section{Conflict of Interests}

The authors declare that there is no conflict of interests regarding the publication of this paper.

\section{Authors' Contribution}

Hongbin Cheng and Jia Li contributed equally to this work.

\section{Acknowledgments}

This work was supported by PCSIRT (IRT-14R48), NNSF of China (51272158), Changjiang Scholar Incentive Program ([2009]17), and China Postdoctoral Science Foundation (2014M551427).

\section{References}

[1] J. Yoo, Y. Hong, S. J. An et al., "Photoluminescent characteristics of Ni-catalyzed GaN nanowires," Applied Physics Letters, vol. 89, no. 4, Article ID 043124, 2006.

[2] J. M. Myoung, K. H. Shim, C. Kim et al., "Optical characteristics of p-type GaN films grown by plasma-assisted molecular beam epitaxy," Applied Physics Letters, vol. 69, no. 18, pp. 2722-2724, 1996.

[3] F. Qian, Y. Li, S. Gradecak, D. Wang, C. J. Barrelet, and C. M. Lieber, "Gallium nitride-based nanowire radial heterostructures for nanophotonics," Nano Letters, vol. 4, no. 10, pp. 19751979, 2004.

[4] H.-J. Choi, J. C. Johnson, R. He et al., "Self-organized GaN quantum wire UV lasers," Journal of Physical Chemistry B, vol. 107, no. 34, pp. 8721-8725, 2003.

[5] Y. Huang, X. F. Duan, Y. Cui, and C. M. Lieber, "Gallium nitride nanowire nanodevices," Nano Letters, vol. 2, no. 2, pp. 101-104, 2002.

[6] S. Lee and S. Lee, "Current transport mechanism in a metalGaN nanowire Schottky diode," Nanotechnology, vol. 18, no. 49, Article ID 495701, 2007.

[7] E. L. Li, Z. Cui, Y. B. Dai, D. N. Zhao, and T. Zhao, "Synthesis and field emission properties of GaN nanowires," Applied Surface Science, vol. 257, no. 24, pp. 10850-10854, 2011.

[8] D. K. T. Ng, M. H. Hong, L. S. Tan, Y. W. Zhu, and C. H. Sow, "Field emission enhancement from patterned gallium nitride nanowires," Nanotechnology, vol. 18, no. 37, Article ID 375707, 2007.

[9] W. Q. Han, S. S. Fan, Q. Q. Li, and Y. D. Hu, "Synthesis of gallium nitride nanorods through a carbon nanotube-confined reaction," Science, vol. 277, no. 5330, pp. 1287-1289, 1997.

[10] K. Lekhal, G. Avit, Y. André et al., "Catalyst-assisted hydride vapor phase epitaxy of GaN nanowires: exceptional length and constant rod-like shape capability," Nanotechnology, vol. 23, no. 40, Article ID 405601, 2012.

[11] H.-J. Choi, H.-K. Seong, J. Chang et al., "Single-crystalline diluted magnetic semiconductor GaN:Mn nanowires," Advanced Materials, vol. 17, no. 11, pp. 1351-1356, 2005.

[12] S. D. Hersee, X. Sun, and X. Wang, "The controlled growth of GaN nanowires," Nano Letters, vol. 6, no. 8, pp. 1808-1811, 2006.

[13] J.-H. Park, R. Navamathavan, Y.-B. Ra, Y.-H. Ra, J.-S. Kim, and C.-R. Lee, "The growth behavior of GaN NWs on $\mathrm{Si}(111)$ by the dispersion of Au colloid catalyst using pulsed MOCVD," Journal of Crystal Growth, vol. 319, no. 1, pp. 31-38, 2011. 
[14] K. Choi, M. Arita, and Y. Arakawa, "Selective-area growth of thin GaN nanowires by MOCVD," Journal of Crystal Growth, vol. 357, no. 1, pp. 58-61, 2012.

[15] C. Samanta, D. S. Chander, J. Ramkumar, and S. Dhamodaran, "Catalyst and its diameter dependent growth kinetics of CVD grown GaN nanowires," Materials Research Bulletin, vol. 47, no. 4, pp. 952-956, 2012.

[16] D. H. Kuo, H. C. Yang, and J. Y. Cheng, "Catalytic effects on the growth of $\mathrm{GaN}$ nanowires by chemical vapor deposition with different $\mathrm{Ga}$ sources of $\mathrm{GaCl}_{3}$ and $\mathrm{Ga}_{2} \mathrm{Cl}_{4}$," Journal of the Electrochemical Society, vol. 158, no. 2, pp. 47-51, 2011.

[17] X. M. Cai, A. B. Djurišić, and M. H. Xie, "GaN nanowires: CVD synthesis and properties," Thin Solid Films, vol. 515, no. 3, pp. 984-989, 2006.

[18] H. Q. Wu, H.-Y. Cha, M. Chandrashekhar, M. G. Spencer, and G. Koley, "High-yield GaN nanowire synthesis and field-effect transistor fabrication," Journal of Electronic Materials, vol. 35, no. 4, pp. 670-674, 2006.

[19] J. H. Chen, C. S. Xue, H. Z. Zhuang et al., "Catalytic synthesis of large-scale GaN nanorods," Materials Research Bulletin, vol. 43, no. 11, pp. 2974-2978, 2008.

[20] M. Narukawa, S. Koide, H. Miyake, and K. Hiramatsu, "Growth of undoped and Zn-doped GaN nanowires," Journal of Crystal Growth, vol. 311, no. 10, pp. 2970-2972, 2009.

[21] Q. N. Abdullah, F. K. Yam, J. J. Hassan, C. W. Chin, Z. Hassan, and M. Bououdina, "High performance room temperature GaN-nanowires hydrogen gas sensor fabricated by chemical vapor deposition (CVD) technique," International Journal of Hydrogen Energy, vol. 38, no. 32, pp. 14085-14101, 2013.

[22] S. Nath Das, S. Patra, J. Prakash Kar et al., "Growth and characterization of $\mathrm{Mg}$-doped $\mathrm{GaN}$ nanowire synthesized by the thermal evaporation method," Materials Letters, vol. 106, pp. 352-355, 2013.

[23] M. K. Ren, H. Huang, H. B. Wu et al., "Growth of high quality $\mathrm{GaN}$ nanowires by using $\mathrm{Ga} / \mathrm{GaCl}_{3}$ sources," Physica E: LowDimensional Systems and Nanostructures, vol. 57, pp. 145-148, 2014.

[24] L. L. Low, F. K. Yam, K. P. Beh, and Z. Hassan, "The influence of $\mathrm{Ga}$ source and substrate position on the growth of low dimensional GaN wires by chemical vapour deposition," Applied Surface Science, vol. 257, no. 23, pp. 10052-10055, 2011.

[25] B.-S. Xu, L.-Y. Zhai, J. Liang, S.-F. Ma, H.-S. Jia, and X.-G. Liu, "Synthesis and characterization of high purity GaN nanowires," Journal of Crystal Growth, vol. 291, no. 1, pp. 34-39, 2006.

[26] S. B. Xue, H. Z. Zhuang, C. S. Xue, and L. J. Hu, "Synthesis of GaN nanorods by ammoniating $\mathrm{Ga}_{2} \mathrm{O}_{3} / \mathrm{ZnO}$ films," Chinese Physics Letters, vol. 23, no. 11, pp. 3055-3057, 2006.

[27] G. Jacob, R. Madar, and J. Hallais, "Optimized growth conditions and properties of N-type and insulating GaN," Materials Research Bulletin, vol. 11, no. 4, pp. 445-450, 1976.

[28] C. C. Chen and C. C. Yeh, "Large-scale catalytic synthesis of crystalline gallium nitride nanowires," Advanced Materials, vol. 12, no. 10, pp. 738-741, 2000. 

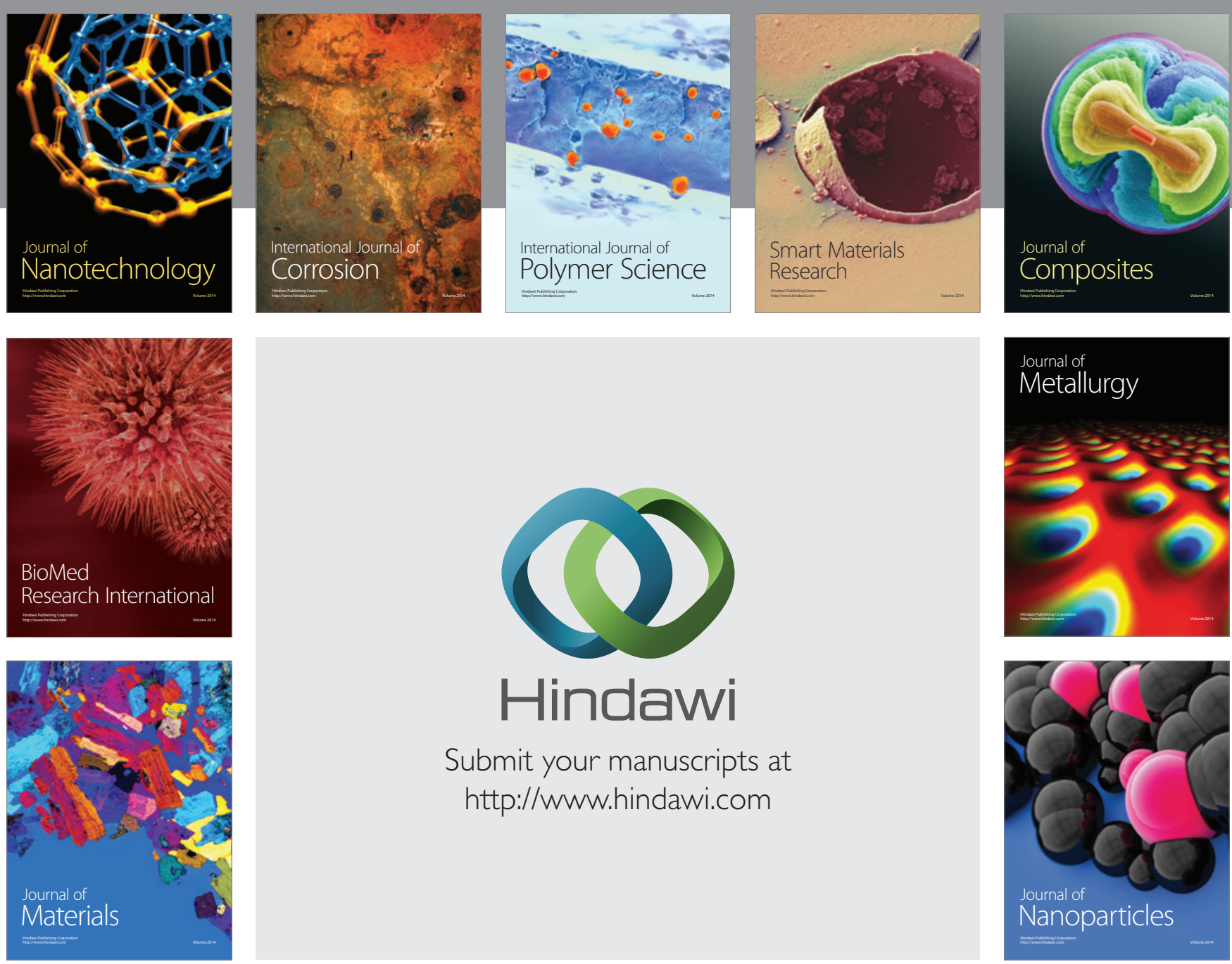

Submit your manuscripts at http://www.hindawi.com
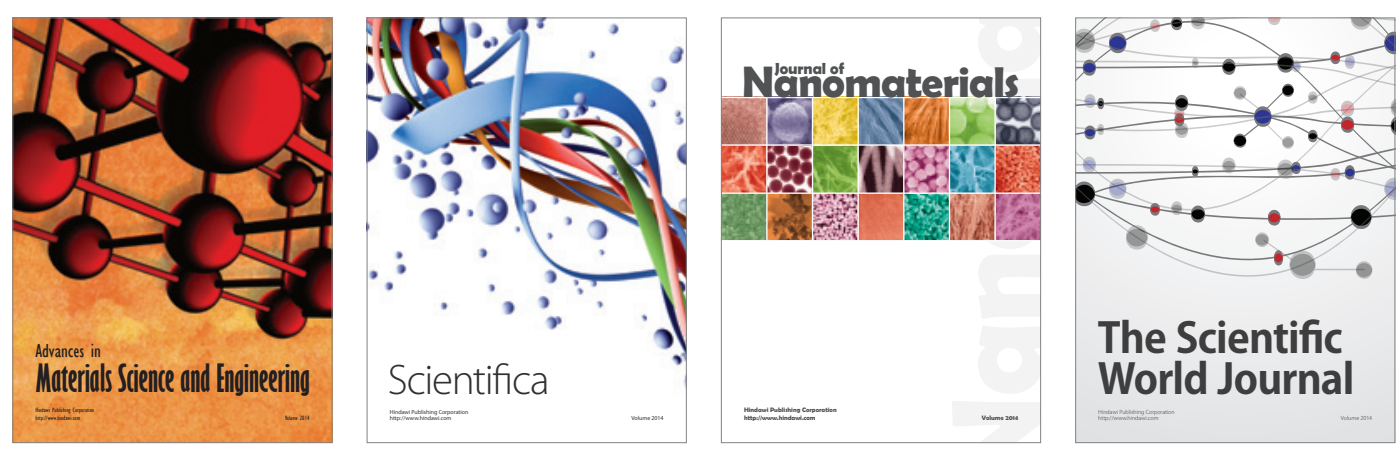

\section{The Scientific World Journal}
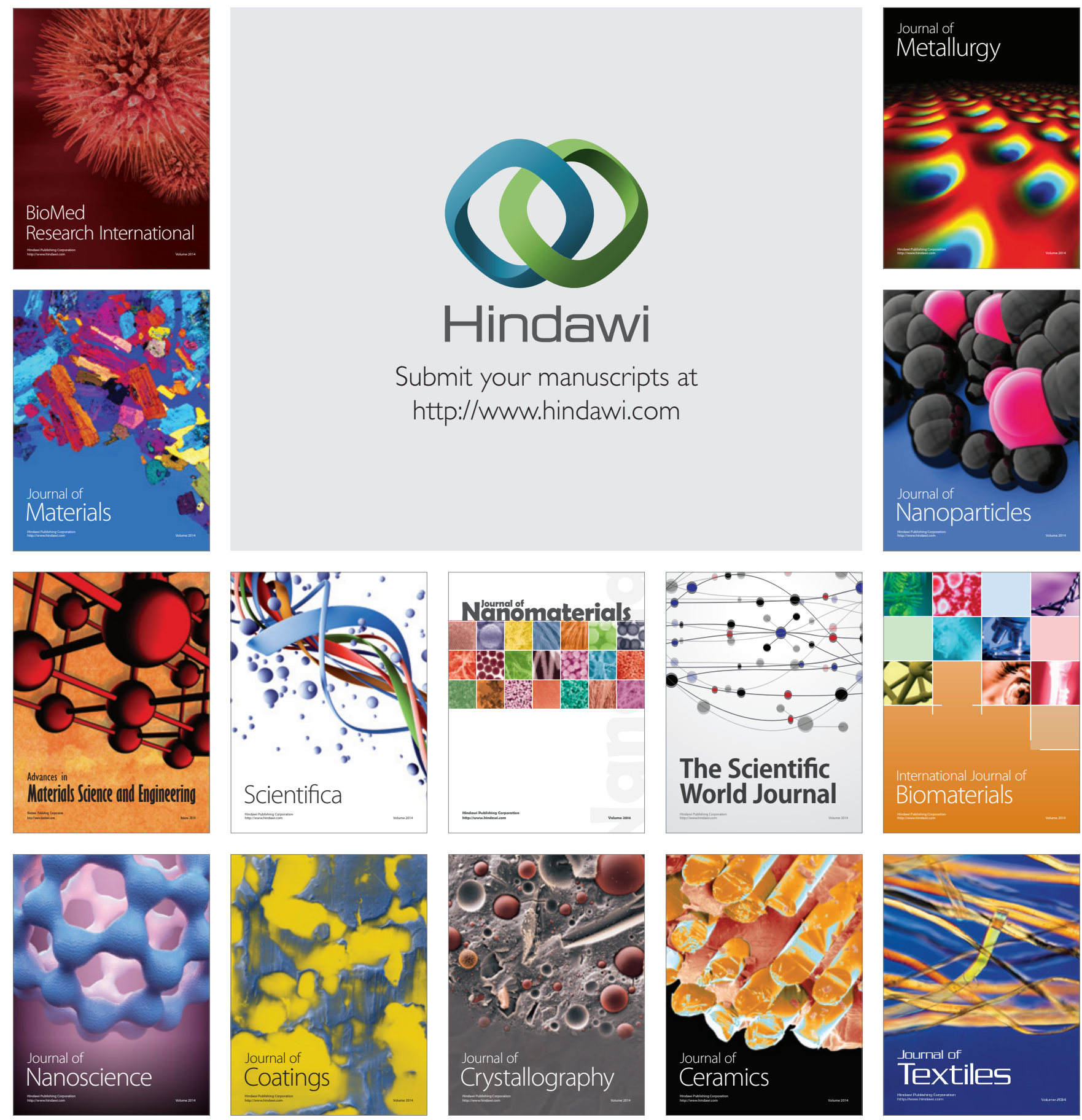